\title{
A PREPARAC̣̃̃O PARA A DOCÊNCIA NO ENSINO FUNDAMENTAL NA VISÃO DE LICENCIANDOS EM CIÊNCIAS NATURAIS E CIÊNCIAS BIOLÓGICAS
}

\author{
PEDRO AMARILHO ALMEIDA MACEDO ${ }^{*}$ \\ https://orcid.org/0000-0001-6828-567X \\ RITA DE CÁSSIA REIS ${ }^{* *}$ \\ https://orcid.org/0000-0003-4839-9826
}

RESUMO: Neste artigo discutimos sobre a formação docente para atuar no Ensino Fundamental a partir das percepções de estudantes de dois cursos de licenciatura: um em Ciências Biológicas e outro em Ciências Naturais. A metodologia utilizada envolveu a aplicação de um questionário com itens abertos e fechados que nos permitiu elencar pontos de convergência e divergência entre os dois percursos formativos investigados. Para os licenciandos, seus cursos desenvolvem os conhecimentos necessários para atuarem como docentes e reforçam sua escolha pela profissão. Por outro lado, eles sinalizam que os cursos deveriam rever suas matrizes curriculares, no que diz respeito à abordagem dos conhecimentos disciplinares. Acreditamos que essa discussão seja válida para pensarmos em processos formativos que valorizem a docência nessa etapa da escolarização.

Palavras-chave: Ensino Fundamental. Ciências da Natureza. Formação de professores.

\section{LA PREPARACIÓN PARA LA DOCENCIA EN LA EDUCACIÓN PRIMARIA EN LA VISIÓN DE ESTUDIANTES DE LAS CARRERAS DE CIENCIAS NATURALES Y CIENCIAS BIOLÓGICAS}

RESUMEN: En este artículo, discutimos la formación docente para actuar en la Educación Primaria desde las percepciones de estudiantes de dos carreras de formación docente: una en Ciencias Biológicas y otra en Ciencias Naturales. La metodología que se utilizó involucró la aplicación de un cuestionario con ítems abiertos y cerrados que nos permitieron enumerar puntos de convergencia y divergencia entre los dos itinerarios formativos investigados.

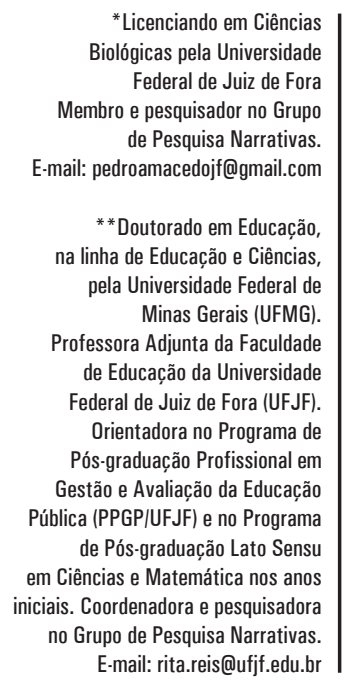

*Licenciando em Ciências lógicas pela Universidade Federal de Juiz de Fora e pesquisador no Grupo de Pesquisa Narrativas.
-mail: pedroamacedojf@gmail.com

* *Doutorado em Educação, a linha de Educação e Ciências, niversidade Federal de Minas Gerais (UFMG). ofessora Adjunta da Faculdade de Educação da Universidade Federal de Juiz de Fora (UFJF). Orientadora no Programa de Pós-graduação Profissional em Gestão e Avaliação da Educação Pública (PPGP/UFJF) e no Programa de Pós-graduação Lato Sensu em Ciências e Matemática nos anos no Grupo de Pesquisa Narrativas. E-mail: rita.reis@ufjf.edu.br

I Universidade Federal de Juiz de Fora, Faculdade de Educação, Juiz de Fora, MG - Brasil. 
Para los estudiantes, sus carreras desarrollan los conocimientos necesarios para que actúen como maestros y reafirman su elección por la profesión. Por otra parte, señalan que los cursos deberían rever sus matrices curriculares con relación al enfoque de los conocimientos disciplinarios. Creemos que esa discusión sea válida, para que pensemos en los procesos formativos que valoren la docencia en esa etapa de la escolaridad.

Palabras clave: Educación Primaria. Ciencia de la Naturaleza. Formación de maestros.

\section{THE PREPARATION FOR TEACHING IN ELEMENTARY SCHOOL IN THE VIEW OF UNDERGRADUATE STUDENTS IN NATURAL SCIENCES AND BIOLOGICAL SCIENCES}

ABSTRACT: This article discusses teacher training to work in Elementary School based on the perceptions of students in two undergraduate courses: one in Biological Sciences and the other in Natural Sciences. The methodology used involves the application of dissertative and multiple-choices questionnaire that allows us to list points of convergence and divergence between the two training paths investigated. For undergraduates, their courses develop the basic knowledge to act as teachers and reinforce their profession choice. On the other hand, they believe that the courses should review their curriculum courses in regard to the approach to disciplinary knowledge. We believe that this discussion is valid to think about training processes that value teaching at this stage of schooling.

Keywords: Elementary School. Natural Sciences. Teacher training. 


\title{
INTRODUÇÃO
}

Ciências - Ciências da Natureza, ${ }^{1}$ para nós - "é uma área que abrange conhecimentos construídos disciplinarmente pela Física, Química, Biologia, Astronomia e Geologia" (LIMA; LOUREIRO, 2013, p.18). Ela possui como particularidade o diálogo constante entre essas áreas de tal forma que os saberes de uma área modificam e complementam os saberes da outra. Nessa perspectiva, buscase selecionar as ideias estruturadoras (LIMA; AGUIAR JR; BRAGA, 1999; LIMA; AGUIAR JR., 2000; MARTINS et al., 2003; LIMA; BARBOZA, 2005; LIMA; SILVA, 2012; LIMA; LOUREIRO, 2013) de cada área que corroborem para o desenvolvimento do pensamento científico e para a compreensão dos fenômenos da natureza. Logo, é uma área que possui como essência a interdisciplinaridade e integração dos saberes.

Alguns estudos (SOMMERMAN, 2006; BERTI; FERNANDEZ, 2015) demonstram que o conceito de interdisciplinaridade é polissêmico, apresentando diversas conceituações na literatura acadêmica. Em nosso estudo, consideramos que a interdisciplinaridade pode possibilitar a comunicação entre disciplinas (conhecimentos disciplinares) e promover a integração de conceitos de tal modo que os especialistas possam entrar em diálogo. Para Sommerman (2006), isso requer trocas intersubjetivas e o reconhecimento pelos especialistas de que cada um deles possui saberes teóricos, práticos e existenciais que são importantes. Isso porque

\begin{abstract}
a hiperespecialização fez com que o aprofundamento de cada disciplina as conduzisse às fronteiras de outras disciplinas, suscitando uma interdisciplinaridade que ou criou novas disciplinas, ou transferiu métodos de uma disciplina para outra, ou abriu corredores para o diálogo entre elas e para a resolução de problemas. [...] Além disso, o aprofundamento de cada disciplina e a aproximação pela hiperespecialização também cooperou para a percepção dos limites de cada disciplina, do espaço de fronteira entre as disciplinas e da percepção de que qualquer fenômeno humano, social ou natural é composto por diferentes dimensões ou por diferentes níveis. (SOMMERMAN, 2006, p.35)
\end{abstract}

Partindo desse pressuposto, acreditamos que a disciplina escolar Ciências da Natureza possui características singulares, pois lida com saberes de diferentes áreas e com uma abordagem interdisciplinar; trabalha com ideias estruturadoras para o pensamento científico, que também auxiliarão no desenvolvimento do estudante nas disciplinas de Química, Física e Biologia; aborda os conteúdos de maneira recorrente ao longo dos anos, de modo tal que os questionamentos fiquem gradativamente mais complexos. Além disso, introduz os estudantes em uma nova cultura, que possui uma forma de pensar e uma linguagem distintas daquelas que o estudante utiliza no seu dia a dia (DRIVER et al., 1999). Por sua vez, isso não quer dizer que esta não seja importante, mas que as diferentes culturas devem estar em diálogo.

Diante dessas demandas, julgamos que para lecionar no Ensino Fundamental é necessário que o docente tenha uma formação acadêmicoprofissional específica. O profissional que leciona nessa etapa de ensino lida com objetivos, abordagens, questões relacionadas à juventude que também são específicas e que se distanciam das abordagens encontradas nos cursos de licenciatura que preparam para o Ensino Médio. Queremos levantar essa reflexão, 
pois Cachapuz (2012) chama atenção que no ensino de ciências é frequente, entre os professores novatos, ensinar da mesma forma como foram ensinados.

No Brasil, desde a criação das licenciaturas em Ciências Biológicas, em 1963, são os egressos desses cursos que tradicionalmente lecionam a disciplina de Ciências da Natureza no Ensino Fundamental. As diretrizes curriculares para o curso de Ciências Biológicas orientam que a modalidade de licenciatura deve contemplar conteúdos de Química, Física e Saúde para atender ao Ensino Fundamental e Médio, bem como a instrumentação para o ensino de ciências no nível fundamental (AYRES; SELLES, 2014).

Segundo Reis (2016), a partir dos anos 2000 houve um aumento na implantação de cursos de licenciaturas plenas voltados para a formação do professor de Ciências da Natureza para o Ensino Fundamental. Ao contrário dos cursos de Ciências Biológicas, que são ofertados por instituições públicas e privadas nas modalidades de licenciatura e bacharelado, as licenciaturas plenas em Ciências da Natureza são ofertadas, predominantemente, por instituições públicas (federais ou estaduais) e não possuem a modalidade de bacharelado.

Contudo, o número de cursos de Licenciatura em Ciências da Natureza (LCN) é pequeno, se comparado ao número de cursos de Licenciatura em Ciências Biológicas (LCB) ofertados no país. Talvez isso ocorra porque as Diretrizes Curriculares Nacionais para a LCB (BRASIL, 2002) preveem a habilitação para atuar na docência no ensino fundamental e médio, enquanto os cursos de LCN ainda não possuem Diretrizes Curriculares Nacionais aprovadas, e os Projetos Pedagógicos de Curso consultados por Reis (2016) previam que a atuação dos egressos desses cursos seria preferencialmente no Ensino Fundamental.

Nesse sentido, temos um cenário no qual, de um lado, nos deparamos com dois perfis de formação docente distintos para atuação no ensino de Ciências da Natureza no Ensino Fundamental e, de outro, com as especificidades desse nível de escolarização. Desse modo, nossa pesquisa teve como objetivo traçar pontos de convergência e divergência entre esses dois perfis de formação a partir das demandas impostas para atuação no ensino de Ciências da Natureza no nível fundamental.

Para isso, nos baseamos na pesquisa realizada por Reis (2016) com licenciandos em Ciências da Natureza de uma universidade pública da região Centro-Oeste, na qual a autora tinha como um dos objetivos investigar suas percepções sobre sua formação e o ensino de Ciências. Utilizamos os mesmos instrumentos de pesquisa para levantar as percepções dos licenciandos em Ciências Biológicas da Universidade Federal de Juiz de Fora/MG. Nosso intuito foi traçar um paralelo entre as vivências formativas de ambos os grupos e as visões sobre o ensino de Ciências da Natureza no nível fundamental. Nesse contexto, ressaltamos que utilizamos os mesmos critérios de inclusão na pesquisa adotados por Reis (2016) para a seleção dos licenciandos em Ciências Biológicas.

\section{A FORMAC̣̃̃O DE PROFESSORES DE CIÊNCIAS DA NATUREZA}

Ao propormos nesta pesquisa uma reflexão sobre o docente que leciona Ciências da Natureza, utilizamos o termo formação acadêmico-profissional (DINIZ-PEREIRA, 2010) para nos referirmos aos cursos de licenciatura, no 
lugar de formação inicial, pois ela não é apenas uma formação acadêmica, mas é também profissional por trazer em si elementos que contribuem para o status da profissão e para a constituição da identidade docente. Além disso, não termina com a conclusão da licenciatura. Nesse momento, inicia-se uma nova etapa do processo - o desenvolvimento profissional, com novos desafios, contextos e atores.

Para Cachapuz (2012, p. 26), “[...] a formação de professores implica praticar a teoria (sobretudo na formação inicial) e teorizar a prática (sobretudo na formação contínua). As duas vertentes são indissociáveis".

Em relação à formação de professores nas áreas disciplinares, em Ciências, por exemplo, segundo Gatti, em pleno século XXI "mesmo com as orientações mais integradoras quanto à relação "formação disciplinar/formação para a docência", na prática ainda se verifica a prevalência do modelo consagrado no início do século XX para essas licenciaturas" (GATTT, 2010, p. 1357). Neste, os estudantes cursavam três anos de disciplinas de conhecimento específico da área de atuação (obtendo o título de bacharel) e mais um ano de disciplinas pedagógicas (obtendo o título de licenciado), que ficou conhecido como modelo 3+1.

Além dessa fragmentação entre a formação disciplinar e a formação para a docência, percebe-se nos cursos de formação de professores de Ciências a falta de unidade entre as áreas disciplinares que compõem a disciplina escolar Ciências. Em alguns casos, conforme apontado por um estudo de Gatti e Nunes (2009) sobre a formação de professores para o Ensino Fundamental, há cursos de Ciências Biológicas que nem sequer contemplam os conhecimentos de Química e Física necessários para atuar no Ensino Fundamental.

Para Cunha e Krasilchick (2000, p. 2 e 3),

no que diz respeito às Licenciaturas em Ciências Biológicas, estejam elas vinculadas ou não aos Bacharelados, incluindo aqui também os cursos bem conceituados, estão longe de formar adequadamente o professor de Ciências para o Ensino Fundamental, em vista de seus currículos altamente biologizados. Da mesma forma ocorre nos cursos de Licenciatura em Física e em Química, também pela concentração de disciplinas em suas áreas específicas. Insistir que os cursos de Biologia, Química ou Física priorizem a formação do professor de Ciências tem sido uma batalha para os formadores de professores, mas a prioridade nesses cursos não é esta, principalmente quando o curso apresenta também a modalidade de Bacharelado.

Apesar de esses apontamentos feitos pelas autoras terem duas décadas, sabemos que a preparação para a atuação nos anos finais do Ensino Fundamental não é uma prioridade nos cursos citados. Ousamos dizer que essa etapa da escolarização também não tem sido alvo de políticas públicas significativas, se comparada à Educação Infantil ou ao Ensino Médio, por exemplo.

Assumimos a hipótese de que o docente que atua nos anos finais do Ensino Fundamental, assim como qualquer professor de outra área disciplinar, irá refletir sua visão sobre o que é ensinar e como se aprende, baseado em suas experiências prévias na Educação Básica e na formação acadêmico-profissional. Logo, é necessário que o curso de licenciatura forneça as bases científicas e pedagógicas adequadas para a formação de um professor, para que este seja capaz 
de lecionar de forma coerente com as necessidades educativas dos estudantes dos anos finais do Ensino Fundamental, que têm um perfil diferente dos estudantes do Ensino Médio (RAZUCK; ROTTA, 2014).

Nesse caso, a literatura indica que ao conteúdo a ser ensinado, de necessário domínio pelo professor, acrescentam-se conhecimentos relacionados à História e à Filosofia das Ciências, aos direcionamentos metodológicos empregados na construção de conhecimentos científicos, às interações entre Ciência, Tecnologia, Sociedade e Ambiente, e às limitações e perspectivas do desenvolvimento científico. Todos esses conhecimentos podem embasar um processo de ensino no qual o conteúdo ensinado não seja abordado como pronto, verdadeiro, estático, inquestionável, neutro e descontextualizado social, histórica e culturalmente (SCHNETZLER, 2012).

Pensando na formação de professores de Ciências, Carvalho e Gil-Perez (2011, p. 68) consideram que ela deveria associar as atividades de pesquisa e inovação permanentemente. Além disso, eles indicam a necessidade de promoção de uma mudança didática que questione as concepções de senso comum, em especial aquela de que 'ensinar é fácil'. Para os autores, é importante um profundo conhecimento do conteúdo a ser ensinado (porém, sem visões reducionistas de que só isso basta) e da apropriação, pelo licenciando, de uma visão de ensino e aprendizagem das Ciências como construção de conhecimentos, tanto por parte dos professores como dos alunos.

Contudo, os professores formadores, em especial das áreas de referência, continuam perpetuando essa visão de senso comum sobre a atividade de ensinar. Segundo Schnetzler (2010), esses professores acreditam que a docência é uma atividade que exige o conhecimento dos conteúdos de suas disciplinas de atuação na graduação, e que isso bastaria para preparar os futuros professores para atuarem na Educação Básica.

Por outro lado, os formadores das áreas pedagógicas constatam que a falta de domínio dos conteúdos disciplinares, pelos alunos, prejudica a sua transposição para o saber escolar. Essa constatação, segundo Maldaner e Schnetzler (1998), reforça nos professores formadores das áreas pedagógicas e nos pesquisadores educacionais a crença de que não conseguimos formar bons professores.

Ao observarmos os cursos de licenciatura, percebemos que essa constatação também decorre por causa de uma formação disciplinar estanque, que não articula os conhecimentos entre si. Por isso, consideramos importante que as teorias tenham relação e que venham de questões relativas ao ensino.

Além disso, segundo Tardif (2012), é inusitado reconhecer que os professores estão aptos a formar pessoas, mas ao mesmo tempo não se permite que atuem em sua formação, podendo opinar e determinar seus conteúdos e formas de maneira conjunta com outros atores da educação. Logo, como podemos pensar que a formação acadêmico-profissional é o espaço propício para a constituição de uma profissão se o licenciando, em grande parte dos cursos, não possui autonomia sobre seu processo formativo e nem conhecimento sobre as oportunidades de aprendizado durante a graduação como eventos, estágios não obrigatórios, disciplinas optativas etc.?

De modo geral, para Tardif e Lessard (2009), os cursos de formação para a docência são organizados segundo um modelo aplicacionista do conhecimento no qual os licenciandos passam uma grande parte do curso assistindo aulas de disciplinas específicas baseadas em conhecimentos proposicionais. E, logo após, eles estagiam para "aplicarem" os conhecimentos adquiridos. Assim que terminam 
a formação, eles atuam em sala de aula, aprendendo na prática a lecionar. Nesse período, eles constatam que grande parte dos conhecimentos proposicionais vistos na graduação não se aplica à vivência cotidiana da escola.

Ao pesquisar a formação de professores de Ciências norte-americanos, Gunckel (2013) percebeu a dicotomia entre teoria e prática nos cursos de formação de professores. Para a autora, os licenciandos, ao cursarem as disciplinas de estágio supervisionado, sentem que há distorções entre o discurso da universidade e o da escola básica. Nesse momento, os futuros professores permeiam a fronteira universidadeescola e precisam ser levados a refletir sobre os diferentes modos de falar, pensar e agir dessas duas esferas. A pesquisa conclui que os futuros professores de Ciências muitas vezes rejeitam ou modificam as ferramentas ou modelos de ensino introduzidos nos cursos universitários, já que não se identificam com as visões de ensino que levam para as escolas ou não se adaptam às realidades encontradas em sala de aula.

Carvalho e Gil-Pérez (2011) afirmam que durante a formação acadêmicoprofissional deve-se facilitar a integração entre o desenvolvimento do conhecimento dos alunos, das aulas e da natureza do processo educativo com a prática docente. Para os autores, se a metodologia de ensino não é estudada no contexto em que será aplicada, os professores/licenciandos podem não saber identificar os principais aspectos, nem adaptar as estratégias institucionais à sua matéria específica ou às novas situações.

Portanto, a pesquisa que apresentamos busca investigar essas questões relativas à docência no ensino de Ciências da Natureza e que deveriam ser contempladas durante a formação acadêmico-profissional com licenciandos em Ciências Biológicas e com licenciados em Ciências da Natureza, esses últimos a partir dos dados de Reis (2016).

\section{O PERCURSO DE NOSSA PESQUISA}

Esta pesquisa teve como objetivo traçar pontos de convergência e divergência entre as percepções de licenciandos em Ciências da Natureza (CN) e em Ciências Biológicas (CB) sobre sua formação e o ensino de Ciências no nível fundamental. Esses dois grupos de participantes foram compostos por licenciandos em Ciências Biológicas da Universidade Federal de Juiz de Fora/MG (UFJF) e por licenciandos em Ciências da Natureza de uma universidade federal da região Centro-Oeste, esses últimos investigados por Reis (2016).

Para que pudéssemos estabelecer as aproximações e os distanciamentos entre esses dois modelos de formação acadêmico-profissional na visão de quem as vivencia (os licenciandos), utilizamos os mesmos critérios de inclusão propostos por Reis (2016). Foram convidados para participar do estudo todos os licenciandos que cursavam alguma disciplina pedagógica que previa a inserção na escola, seja por meio das Práticas como Componente Curricular ou dos Estágios Supervisionados. Essa abordagem dos estudantes ocorreu em ambos os cursos por meio dos docentes que cederam o espaço necessário, durante suas aulas, para que apresentássemos a pesquisa e aplicássemos o instrumento de coleta de dados, que consistiu em um questionário.

Pretendíamos, com esse instrumento, abranger um número maior de licenciandos investigados e estabelecer algumas relações entre as visões dos estudantes sobre o ensino de Ciências da Natureza e as disciplinas que já cursaram, sobre a formação acadêmico-profissional e a atuação no Ensino Fundamental. 
Com o método de aplicação adotado, conseguimos abranger os estudantes que se encontravam presentes nas aulas. Reis (2016), em seu estudo, conseguiu o retorno de $58 \%$ dos estudantes matriculados a época, totalizando 38 questionários respondidos. E nós conseguimos $67 \%$ dos estudantes matriculados, o que correspondeu a 20 questionários respondidos. Logo, neste estudo, o grupo de respostas compreendeu as percepções de 58 licenciandos.

$\mathrm{O}$ instrumento utilizado por nós com os licenciandos em $\mathrm{CB}$ foi desenhado por Reis (2016), com itens abertos e fechados. Para esta publicação, nos atemos às respostas dadas aos itens fechados, os quais foram construídos seguindo a escala Likert, que se enquadra na categoria de Surveys e permite descrever a população investigada apontando traços e atributos. Nesse tipo de questionário, de modo geral, apresenta-se ao respondente uma declaração e uma pergunta: se ele concorda totalmente, concorda, discorda ou discorda totalmente. A escolha pela escala Likert levou em conta também a redução do tempo de resposta e da dispersão da atenção dos alunos, assim como a possibilidade de comparação entre as respostas, tanto aos pesquisadores quanto aos respondentes.

Segundo Babbie (1999, p. 204), "como os respondentes podem rever rapidamente suas respostas a itens anteriores neste conjunto, podem escolher entre, digamos, "concorda fortemente" e "concorda" com uma declaração, comparando a força da concordância com as respostas anteriores".

O questionário aplicado aos licenciandos em Ciências Biológicas teve de passar por pequenas adaptações no cabeçalho e nos dados sobre o perfil dos estudantes, mas manteve todas as afirmações aplicadas aos licenciandos em Ciências da Natureza. Nossa versão do instrumento contou com 62 itens objetivos. Esses itens buscavam delinear o perfil dos estudantes e suas considerações sobre: o curso, o Ensino Fundamental de Ciências, a forma de abordar os conteúdos ao longo do ensino de ciências e suas experiências durante a escolarização.

Junto com os questionários, entregamos aos licenciandos duas vias de um Termo de Consentimento Livre e Esclarecido, e informamos que a pesquisa foi aprovada pelo Comitê de Ética e Pesquisa da UFJF.

Durante a análise dos questionários, organizamos os posicionamentos dos licenciandos para com as afirmações por meio de blocos que nos permitiram evidenciar os pontos de convergência e divergência em relação à preparação pedagógica, ao conteúdo disciplinar veiculado, à integração curricular vivenciada, à abordagem curricular e metodológica no ensino de Ciências da Natureza no Ensino Fundamental, entre outros aspectos que passamos a apresentar.

\section{ANÁLISE DE DADOS - OS POSICIONAMENTOS DOS LICENCIANDOS}

Nessa análise, estamos interessados em investigar as percepções que os licenciandos em Ciências Biológicas (CB) e em Ciências da Natureza (CN) têm em relação à sua formação e ao ensino de Ciências, ambos voltados para o trabalho docente nos anos finais do Ensino Fundamental. Nesse sentido, nosso intuito não é fazer um estudo comparativo entre os posicionamentos dos grupos de licenciandos investigados no sentido de apontar uma ou outra formação como sendo a mais "adequada", mas evidenciar aspectos convergentes e divergentes entre eles para 
refletirmos sobre suas concepções e como elas dialogam com o ensino de Ciências.

Iniciamos nossa análise com a hipótese de que, com os avanços sociais, novos desafios são impostos ao professor e repercutem na formação acadêmicoprofissional, no exercício da profissão, nas relações de ensino, na carreira e na identidade docente. Para Tardif e Lessard (2009, p. 9), “[...] o trabalho docente representa uma atividade profissional complexa de alto nível, que exige conhecimentos e competências em vários campos: cultura geral e conhecimentos disciplinares [...]", por exemplo. Para Tardif (2012), os cursos de formação acadêmica de professores devem se orientar em torno da formação cultural, que o autor denomina como geral, e a formação científica ou disciplinar.

Desse modo, sobre a visão geral do curso, colocamos quatro afirmações no questionário para que os licenciandos apontassem seu grau de concordância com elas (tabela 1).

Tabela 1. Visão geral do curso

\begin{tabular}{|c|c|c|c|c|c|c|c|c|}
\hline \multirow{2}{*}{$\begin{array}{l}\text { Afirmações sobre a visão } \\
\text { geral do curso }\end{array}$} & \multicolumn{4}{|c|}{ Ciências Naturais (\%) } & \multicolumn{4}{|c|}{ Ciências Biológicas (\%) } \\
\hline & CT & C & D & DT & CT & C & D & DT \\
\hline $\begin{array}{l}\text { Contribui para a aquisição de cultura } \\
\text { geral. }\end{array}$ & 40 & 54 & 3 & 3 & 45 & 45 & 10 & 0 \\
\hline $\begin{array}{l}\text { Contribui para conhecer a realidade da } \\
\text { Educação Básica. }\end{array}$ & 50 & 36 & 9 & 5 & 25 & 75 & 0 & 0 \\
\hline $\begin{array}{l}\text { Reforça minha escolha pela carreira } \\
\text { docente.* }\end{array}$ & 34 & 45 & 16 & 5 & 20 & 45 & 20 & 10 \\
\hline Prepara para o exercício profissional. & 32 & 60 & 5 & 3 & 25 & 70 & 5 & 0 \\
\hline $\begin{array}{l}\text { Contribui para minha formação de } \\
\text { professor de Ciências. }\end{array}$ & 66 & 34 & 0 & 0 & 25 & 70 & 5 & 0 \\
\hline
\end{tabular}

Fonte: Dados adaptados de Reis (2016) e elaborados pelos autores.

* Neste caso, o número de licenciandos em CB não computou 100\%, pois houve um estudante que para essa afirmativa não marcou nenhuma resposta.

Ao afirmarmos que o curso contribui para a aquisição de cultura geral, percebemos que em ambos os grupos de licenciandos a maioria concorda em algum grau. A princípio, é de se esperar que toda formação em nível superior proporcione, ou incentive, o acesso à cultura. Contudo, sabemos que muitos licenciandos não têm o hábito de frequentar, ou não vivenciaram em sua escolarização, visitas a espaços de divulgação cultural. Por isso, temos observado, em algumas propostas curriculares de formação acadêmico-profissional, a destinação de uma disciplina ou um dos estágios supervisionados para serem feitos em espaços não formais de ensino (museus, galerias, parques, centros de ciência etc.), ${ }^{2}$ como é o caso do curso de CB investigado. Entretanto, compreendemos que a noção de cultura é mais ampla e não está circunscrita apenas nos espaços culturais a que tiveram acesso durante a graduação, mas vai além, englobando também as questões da profissão docente. 
No caso da formação docente, existem aspectos culturais que são específicos da profissão/comunidade docente, que compreendem conhecer: o sistema escolar, a história da profissão, a ética profissional, a sociologia da juventude, as dificuldades de aprendizagem, as finalidades e a realidade da Educação Básica, por exemplo. Desse modo, ao Reis (2016) questionar os estudantes de CN se o curso contribuiu para conhecerem essa realidade, $86 \%$ concordaram em algum grau, e constatamos que $100 \%$ dos licenciandos em CB também concordam em algum grau.

Um ponto interessante é que, entre os estudantes de $\mathrm{CB}$, não há a sensação de que não conhecem a realidade da Educação Básica, ao contrário do que ocorre com os estudantes de $\mathrm{CN}$, em que $14 \%$ do grupo sente que as discussões não contribuem para conhecer tal realidade.

Ao possibilitar conhecer a realidade da Educação Básica, pudemos analisar que o curso estaria preparando para o exercício profissional, o que foi confirmado pelos licenciandos em $\mathrm{CB}$ e $\mathrm{CN}$ ao concordarem, em sua maioria, com a afirmação apresentada. Porém, devemos ressaltar que adotar uma profissão como sendo sua abrange questões como a história de vida dos graduandos, o contexto social e outros fatores subjetivos (PIMENTA, 1998), que muitas vezes fogem da alçada dos cursos. Esses fatores seriam justificativas plausíveis, em nosso entendimento, para obtermos percentuais menores de concordância com a afirmação de que o curso reforça a escolha pela carreira docente (tabela 1).

De igual modo, ao afirmarmos junto aos licenciandos em CB que o curso contribui para a formação de professor de Ciências, obtivemos 95\% de concordância em algum grau, muito próximo do que vimos em Reis (2016) para os licenciandos em CN. Porém, diante da afirmação de que o curso reforça a escolha de querer ser professor(a) de Ciências, a porcentagem de concordância em algum grau caiu para $79 \%$ entre os licenciandos em CN. Já para os licenciandos em CB, fizemos essa afirmação e obtivemos $65 \%$ de concordância, total ou parcial.

Esses dados mostram que tais alunos se sentem habilitados em lecionar Ciências no Ensino Fundamental, mas em ambos os grupos encontramos estudantes desmotivados para a docência e, entre os licenciandos em CB, a motivação maior está em atuar no Ensino Médio.

Para Reis (2016, p. 124), "quando os licenciandos falam sobre seu futuro profissional, destacam sua personalidade, suas habilidades e talentos como elementos importantes para um bom trabalho". Desse modo, a autora indica que, para responder aos questionamentos e às reflexões propostas, a maioria se baseia nas experiências que tiveram ao longo da escolarização. Por isso, no questionário, propusemos algumas afirmações que versavam sobre as disciplinas de ensino ${ }^{3}$ e sua relação com o Ensino Fundamental e a carga horária referente a essas disciplinas na matriz curricular, conforme exposto na tabela 2. Pois Fernandez (2011), ao refletir sobre os estudos de Shulman, afirma que o conhecimento pedagógico do conteúdo é uma categoria específica do conhecimento dos professores dentro da categoria do conhecimento prático. 
Tabela 2. Posicionamentos sobre a preparação pedagógica

\begin{tabular}{lllllllllll}
\hline \multirow{2}{*}{$\begin{array}{c}\text { Afirmações sobre a } \\
\text { preparação pedagógica }\end{array}$} & \multicolumn{8}{c}{ Ciências Naturais (\%) } & \multicolumn{6}{c}{ Ciências Biológicas (\%) } \\
\cline { 2 - 9 } & CT & C & D & DT & CT & C & D & DT \\
\hline $\begin{array}{l}\text { Possui carga horária suficiente de } \\
\text { disciplinas de ensino (pedagógicas).* }\end{array}$ & 55 & 34 & 8 & 3 & 30 & 50 & 10 & 5 \\
\hline $\begin{array}{l}\text { Relaciona o conteúdo das disciplinas } \\
\text { de ensino (pedagógicas) com o Ensino } \\
\begin{array}{l}\text { Fundamental de ciências. } \\
\hline\end{array}\end{array}$ & 24 & 52 & 21 & 3 & 20 & 50 & 25 & 5 \\
\hline
\end{tabular}

Fonte: Dados adaptados Reis (2016) e elaborados pelos autores.

*Neste caso, o número de licenciandos em CB não computou 100\%, pois houve um estudante que para essa afirmativa não marcou nenhuma resposta.

Quando questionamos os estudantes de $\mathrm{CN}$ se o curso possui uma carga horária suficiente de disciplinas de ensino, percebemos que 34\% concordam, 55\% concordam totalmente e $11 \%$ discordam em algum grau. Verificamos, também, que $50 \%$ dos estudantes de CB concordam que a carga horária é suficiente, enquanto $30 \%$ concordam totalmente. Apesar de observarmos um comportamento próximo entre os licenciandos de ambos os cursos, podemos destacar que a satisfação com a carga horária das disciplinas de ensino é maior entre os licenciandos de $\mathrm{CN}$.

Acreditamos que existe mais de um fator que possa influenciar na percepção dos licenciandos sobre a carga horária das disciplinas de ensino, como: a distribuição dessas disciplinas ao longo dos semestres desde o início do curso, o que proporciona um contato contínuo com as mesmas; a carga horária destinada às práticas como componente curricular; e a carga horária destinada aos estágios. Alguns desses fatores foram apontados na pesquisa de Reis (2016) pelos coordenadores de curso de $\mathrm{CN}$ analisados pela autora.

Para a afirmação de que o curso relaciona o conteúdo das disciplinas de ensino (pedagógicas) com o ensino de Ciências no nível fundamental, 24\% dos estudantes de $\mathrm{CN}$ demonstraram concordar totalmente. Somando as respostas daqueles licenciandos de $\mathrm{CN}$ que discordam ou discordam totalmente da afirmativa, temos a mesma taxa de $24 \%$.

Quando apresentada a mesma afirmativa aos licenciandos de CB, 20\% demonstraram concordância total, em detrimento ao somatório daqueles que discordaram em algum grau, chegando a 30\% das respostas. Consideramos que, em ambos os cursos, os estudantes que concordam totalmente com a afirmativa são aqueles que conseguem perceber a relação entre as disciplinas de ensino e o Ensino Fundamental, mesmo que essa relação não esteja evidenciada pelas ementas e práticas das disciplinas. Em contrapartida, aqueles que discordam em algum grau não conseguem evidenciar tal relação, incitando em nós o seguinte questionamento: se há uma preocupação dessas disciplinas em abordar o ensino de Ciências no nível fundamental ou se é o estudante que não consegue ter um olhar para a docência nesse nível.

No caso dos alunos que concordam, mas não totalmente - $52 \%$ das respostas em $\mathrm{CN}$ e $50 \%$ em $\mathrm{CB}$-, presumimos que eles tenham a percepção de que as relações entre o conteúdo das disciplinas de ensino (pedagógicas) com o Ensino Fundamental são realizadas em menor proporção diante de outras 
temáticas abordadas no curso. Portanto, ainda que os índices apresentados para a afirmativa à primeira vista nos levem a crer que os cursos de CN e CB estabelecem relações entre as disciplinas pedagógicas e o Ensino Fundamental, o conjunto de dados apresentados anteriormente não nos permite fazer essa afirmação.

Do igual modo, observamos esse mesmo movimento entre os licenciandos quando indagamos sobre a relação estabelecida entre os conhecimentos do conteúdo e o Ensino Fundamental, já que ela não ficou evidente pelas respostas obtidas na tabela 3. Ao questionarmos os licenciandos sobre o conhecimento do conteúdo, pretendíamos elucidar como eles analisavam a distribuição de carga horária entre as áreas disciplinares que compõem o currículo de Ciências da Natureza no Ensino Fundamental, de acordo com as experiências que viveram ao longo do curso e das demandas que eles acreditam que terão durante a atuação na Educação Básica.

Sabemos que, tradicionalmente, na literatura acadêmica, há a descrição de um modelo de formação de professores que se configura como um apêndice dos cursos de bacharelado. Esse modelo ficou conhecido como 3+1, sendo caracterizado pelo predomínio dos conteúdos a serem ensinados em detrimento dos conteúdos pedagógicos e pedagógicos de conteúdo, conforme discutimos anteriormente. Assim, apresentamos no questionário seis afirmações, que estão dispostas na tabela 3, sobre o conhecimento do conteúdo a ser veiculado nos cursos.

Tabela 3. Posicionamentos sobre o conhecimento do conteúdo

\begin{tabular}{|c|c|c|c|c|c|c|c|c|}
\hline \multirow{2}{*}{$\begin{array}{c}\text { Afirmações sobre o } \\
\text { conhecimento do conteúdo }\end{array}$} & \multicolumn{4}{|c|}{ Ciências Naturais [\%] } & \multicolumn{4}{|c|}{ Ciências Biológicas (\%) } \\
\hline & Ст & C & D & DT & CT & C & D & DT \\
\hline $\begin{array}{l}\text { Prepara para a aquisição de formação } \\
\text { teórica nas áreas de Química, Física, } \\
\text { Biologia e Geologia. }\end{array}$ & 37 & 50 & 13 & 0 & 5 & 60 & 25 & 10 \\
\hline $\begin{array}{l}\text { Possui carga horária suficiente de } \\
\text { disciplinas de Química. }\end{array}$ & 31 & 53 & 16 & 0 & 15 & 25 & 30 & 30 \\
\hline $\begin{array}{l}\text { Possui carga horária suficiente de } \\
\text { disciplinas de Biologia. }\end{array}$ & 24 & 42 & 31 & 3 & 55 & 35 & 10 & 0 \\
\hline $\begin{array}{l}\text { Possui carga horária suficiente de } \\
\text { disciplinas de Geologia. }\end{array}$ & 24 & 34 & 37 & 5 & 10 & 20 & 30 & 40 \\
\hline $\begin{array}{l}\text { Possui carga horária suficiente de } \\
\text { disciplinas de Física. }\end{array}$ & 29 & 53 & 18 & 0 & 15 & 20 & 35 & 30 \\
\hline $\begin{array}{l}\text { Relaciona o conteúdo das disciplinas de } \\
\text { Química, Biologia, Física e Geologia com o } \\
\text { Ensino Fundamental de ciências.* }\end{array}$ & 24 & 47 & 26 & 3 & 0 & 25 & 55 & 15 \\
\hline
\end{tabular}

Fonte: Dados adaptados de Reis (2016) e elaborados pelos autores.

${ }^{*}$ Neste caso, o número de licenciandos em CB não computou 100\%, pois houve um estudante que para essa afirmativa marcou duas respostas, desse modo, desconsideramos seu posicionamento para essa afirmativa. 
Ao afirmarmos para os licenciandos de $\mathrm{CN}$ que o curso prepara para a aquisição de formação teórica nas áreas de Química, Física, Biologia e Geologia, $50 \%$ concordaram com essa afirmação, 37\% concordaram totalmente e 13\% discordaram. Analisando apenas essa afirmação, notamos que os licenciandos de CN concordam que há uma preparação teórica no curso nas áreas disciplinares que compõem o currículo de Ciências da Natureza no Ensino Fundamental. Contudo, ao comparar as taxas de concordância e discordância desta afirmação ao grau de concordância com as demais afirmações que versam sobre a satisfação em relação à carga horária das áreas de Química, Física, Biologia e Geologia, respectivamente, constatamos que o grau de discordância aumenta.

Comparando com o posicionamento dos licenciandos de $\mathrm{CN}$, notamos que, para eles, a discordância com a carga horária destinada às áreas de Química e Física são relativamente próximas, $16 \%$ e 18\%, respectivamente. Se analisarmos a afirmação que trata da carga horária de Biologia, veremos que 34\% discordam que a mesma seja suficiente para prepará-los para atuar no Ensino Fundamental. Essa constatação ficou evidente durante as falas dos licenciandos entrevistados por Reis (2016), que apontaram, em sua maioria, a falta de uma disciplina que discuta a temática do corpo humano, por exemplo. A autora evidenciou que esse descontentamento está relacionado com os estágios supervisionados desses licenciandos que, ao chegarem nas escolas campo de estágio, relatavam se deparar com um currículo de ciências biologizado e com uma abordagem tradicional.

Um movimento diferente acontece entre os licenciandos em $\mathrm{CB}$, que acreditam que a carga horária destinada aos conhecimentos da área de Biologia seja suficiente, o que, pela natureza do curso, já era esperado por nós. Porém, em relação à carga horária destinada para estudo e discussão dos conteúdos relativos à Química, Física e Geologia, mostra um grau de insatisfação elevado por parte dos licenciandos.

A partir desses dados, vemos que os alunos de $\mathrm{CN}$, apesar de se sentirem mais preparados para a atuação no Ensino Fundamental, sentem que a abordagem dos conteúdos biológicos e geológicos é insuficiente. Isso talvez seja reflexo das vivências durante as práticas e os estágios em salas de aulas, cuja realidade seja um ensino de ciências biologizado. Por outro lado, os estudantes de CB não desenvolvem esse estranhamento com um ensino de ciências biologizado, mas com os conhecimentos relativos à Química, Física e Geologia.

Desse modo, para Calderhead (1986), citado por Carvalho e Gil-Pérez (2011), um dos obstáculos durante a formação acadêmico-profissional "[...] não é tanto o desenvolvimento do conhecimento dos alunos, das aulas e da natureza do processo educativo, e sim como facilitar aos professores em formação a integração destes conhecimentos dentro de sua própria prática" (CARVALHO; GIL-PEREZ, 2011, p. 80). Por isso, para elucidarmos a integração curricular estabelecida nos cursos, apresentamos cinco afirmações nos questionários (tabela 4). 
Tabela 4 . Posicionamentos sobre a integração curricular

\begin{tabular}{|c|c|c|c|c|c|c|c|c|}
\hline \multirow{2}{*}{$\begin{array}{l}\text { Afirmações sobre a } \\
\text { integração curricular }\end{array}$} & \multicolumn{4}{|c|}{ Ciências Naturais (\%) } & \multicolumn{4}{|c|}{ Ciências Biológicas (\%) } \\
\hline & CT & C & D & DT & Ст & C & D & DT \\
\hline $\begin{array}{l}\text { Estabelece a relação entre as disciplinas } \\
\text { de ensino (pedagógicas).* }\end{array}$ & 25 & 64 & 8 & 3 & 15 & 65 & 15 & 0 \\
\hline $\begin{array}{l}\text { Estabelece a relação entre as disciplinas } \\
\text { de Química, Física, Biologia e Geologia. }\end{array}$ & 24 & 44 & 27 & 5 & 15 & 45 & 25 & 15 \\
\hline $\begin{array}{l}\text { Aborda a interdisciplinaridade (integração) } \\
\text { entre as áreas: Química, Física, Biologia e } \\
\text { Geologia. }\end{array}$ & 26 & 32 & 37 & 5 & 10 & 30 & 45 & 15 \\
\hline $\begin{array}{l}\text { Demanda a construção de planejamentos } \\
\text { de aulas interdisciplinares para o Ensino } \\
\text { Fundamental de ciências.** }\end{array}$ & 24 & 60 & 13 & 3 & 5 & 50 & 40 & 0 \\
\hline
\end{tabular}

Fonte: Dados adaptados de Reis (2016) e elaborados pelos autores.

* Neste caso, o número de licenciandos em CB não computou 100\%, pois houve um estudante que para essa afirmativa não marcou nenhuma resposta.

${ }^{*}$ *Neste caso, o número de licenciandos em CB não computou 100\%, pois houve um estudante que para essa afirmativa marcou duas respostas, desse modo, desconsideramos seu posicionamento quando isso ocorreu.

Observando os dados da tabela 4, percebemos que as relações entre as disciplinas pedagógicas e as pedagógicas de conteúdo são mais evidentes do que entre as disciplinas de conteúdo para os licenciandos de ambos os cursos. Por outro lado, ao afirmarmos que o curso aborda a interdisciplinaridade (integração) entre as áreas de Química, Física, Biologia e Geologia, o grau de discordância se eleva entre os estudantes de $\mathrm{CN}$ e $\mathrm{CB}$, evidenciando que podem haver relações entres as disciplinas de conteúdo, mas que essas não necessariamente envolvem abordagens interdisciplinares.

Acreditamos que uma forma de articular esse movimento interdisciplinar dentro dos cursos seja a criação de momentos na matriz curricular (por meio de seminários, projetos, laboratórios, etc) em que a temática da interdisciplinaridade possa ser vivenciada, experimentada e projetada por professores e licenciandos ao longo do curso, num movimento de diálogo, conforme apontado por Sommerman (2006) anteriormente. Isso faria com que a interdisciplinaridade fosse assumida explicitamente como uma característica e que se tornasse mais nítida para os licenciandos.

Ao relacionarmos essa análise com a última afirmação da tabela 4, ou seja, de que os cursos demandam a construção de planejamentos de aulas interdisciplinares para o ensino de Ciências da Natureza no nível fundamental, podemos supor que a abordagem integradora se estabeleça mais nas disciplinas de ensino do que nas de conteúdo. Uma explicação para esse quadro seria que, nas disciplinas de conteúdo, as abordagens interdisciplinares podem perpassar pelas posturas dos professores em trazer exemplos e/ou fatos de outras áreas para enriquecer/ampliar a construção do conhecimento em sala de aula. Enquanto nas disciplinas de ensino essas abordagens se dariam de maneira sistematizada, por meio de atividades.

Acreditamos que as vivências integradoras proporcionadas durante a graduação podem influenciar na visão que os licenciandos pesquisados têm sobre 
o conteúdo veiculado no ensino de Ciências no nível fundamental. Sendo que, na literatura acadêmica, encontramos pesquisas (LIMA; AGUIAR JR., 2000; MARTINS et al., 2003; LIMA; SILVA, 2012; REIS; LOPES, 2011; LIMA; LOUREIRO, 2013) que apontam o excesso de conteúdos e abordagens estanques entre eles e, de igual maneira, indicam a necessidade de haver a integração entre os conhecimentos disciplinares que compõem o currículo de Ciências nessa etapa da escolarização. Por isso, em nosso estudo, procuramos elucidar o grau de concordância dos licenciandos em relação ao conteúdo veiculado no ensino de Ciências e algumas metodologias de ensino destacadas pela comunidade de pesquisa em Educação em Ciências, conforme apresentado nas afirmações presentes na tabela 5 .

Conforme discutimos anteriormente, parece ser consenso entre os licenciandos de ambos os cursos que a abordagem dos conteúdos no ensino de ciências não deve ser estanque, o que pode ser comprovado pelo alto grau de discordância e discordância total com a afirmação: deve abordar conceitos de Física, Química, Biologia e Geologia separadamente em séries diferentes, presente na tabela 5.

Tabela 5. Posicionamentos sobre abordagem do conteúdo e metodologias

\begin{tabular}{|c|c|c|c|c|c|c|c|c|}
\hline \multirow{2}{*}{$\begin{array}{l}\text { Afirmações sobre abordagem do conteúdo e } \\
\text { metodologias }\end{array}$} & \multicolumn{4}{|c|}{ Ciências Naturais (\%) } & \multicolumn{4}{|c|}{ Ciências Biológicas (\%) } \\
\hline & CT & C & D & DT & CT & C & D & DT \\
\hline $\begin{array}{l}0 \text { estudo de conceitos biológicos deve } \\
\text { corresponder a } 75 \% \text { ou mais do currículo } \\
\text { de ciências. }\end{array}$ & 10 & 37 & 40 & 13 & 30 & 15 & 45 & 10 \\
\hline $\begin{array}{l}\text { Deve abordar conceitos de Física, Química, } \\
\text { Biologia e Geologia separadamente em } \\
\text { séries diferentes. }\end{array}$ & 5 & 19 & 41 & 35 & 5 & 10 & 50 & 35 \\
\hline $\begin{array}{l}\text { Deve corresponder ao estudo de conceitos } \\
\text { biológicos com exemplos da Química e da } \\
\text { Física. }\end{array}$ & 29 & 60 & 8 & 3 & 20 & 60 & 20 & 0 \\
\hline $\begin{array}{l}\text { Deve trabalhar com o ensino por } \\
\text { investigação. }\end{array}$ & 66 & 34 & 0 & 0 & 55 & 45 & 0 & 0 \\
\hline $\begin{array}{l}\text { Deve trabalhar com uma abordagem } \\
\text { experimental. }\end{array}$ & 63 & 34 & 3 & 0 & 65 & 35 & 0 & 0 \\
\hline $\begin{array}{l}\text { Deve abordar as relações entre ciência, } \\
\text { tecnologia e sociedade. }\end{array}$ & 74 & 23 & 0 & 3 & 70 & 30 & 0 & 0 \\
\hline $\begin{array}{l}\text { Deve trabalhar com uma abordagem } \\
\text { temática (lixo, saúde, água...). }\end{array}$ & 66 & 34 & 0 & 0 & 80 & 15 & 5 & 0 \\
\hline $\begin{array}{l}\text { Serve para antecipar os conteúdos } \\
\text { abordados no Ensino Médio de Biologia, } \\
\text { Física e Química. }\end{array}$ & 31 & 53 & 13 & 3 & 20 & 55 & 15 & 10 \\
\hline $\begin{array}{l}\text { Exige a transposição do conhecimento } \\
\text { acadêmico em conhecimento escolar. }\end{array}$ & 22 & 65 & 13 & 0 & 60 & 35 & 0 & 5 \\
\hline
\end{tabular}

Fonte: Dados adaptados Reis (2016) e elaborados pelos autores. 
Contudo, constatamos que, em ambos os grupos de licenciandos, a ideia de um ensino de ciências biologizado ainda é forte, pois cerca da metade deles acredita que os conceitos biológicos devam corresponder a 75\%, ou mais, do currículo de ciências. Além disso, percebemos que essa visão que privilegia os conhecimentos biológicos em detrimento dos demais se amplia para uma boa parcela de ambos os grupos de respondentes, pois eles concordam, em algum grau, que o ensino de Ciências corresponderia ao estudo de conceitos biológicos com exemplos da Química e da Física. De certa forma, isso nos preocupa, pois nos leva a questionar qual a visão de integração que esses futuros professores possuem e se essa visão não seria uma reprodução do que eles encontram nas discussões realizadas durante a graduação.

Esses questionamentos são pertinentes para nós, pois, quando indagamos sobre a utilização de diversas abordagens metodológicas, obtivemos uma ampla concordância, que pode ser justificada pelo fato de eles estarem cursando, ou terem cursado, disciplinas que discutiam o caráter teórico-metodológico dessas abordagens. Além disso, uma parte dos respondentes estava cursando uma disciplina de estágio supervisionado, e a outra parte cursava disciplinas que envolviam práticas de ensino. Assim sendo, acreditamos que os posicionamentos dos licenciandos podem refletir a realidade e as experiências vivenciadas por eles no espaço escolar, quando desenvolvem o acompanhamento dos docentes da Educação Básica, ou propõem alguma intervenção na escola em que realizam o estágio e/ou alguma prática.

Destacamos que, para a maioria dos licenciandos de ambos os cursos, o ensino de Ciências exige a transposição do conhecimento acadêmico em conhecimento escolar. Para Bizzo (2009), existe uma diferença entre a Ciência e a disciplina escolar Ciências. Segundo o autor, a Ciência do laboratório busca elaborar explicações do que é desconhecido por meio de posturas e normas pré-estabelecidas, sem ter acesso aos resultados anteriormente. Já a disciplina escolar de Ciências lança mão de um conjunto de procedimentos metodológicos que estão sujeitos a contextos culturais diferentes para alcançar resultados planejados. Enfim, existe "uma diferença fundamental entre a comunicação de conhecimento em congressos científicos, entre cientistas, e a seleção e adaptação de parcelas desse conhecimento para ser utilizado na escola por professores e alunos" (BIZZO, 2009, p.18).

Dessa forma, indicamos a necessidade de se promover nos cursos de graduação discussões mais amplas sobre o currículo praticado na Educação Básica, em especial nos anos finais do Ensino Fundamental. Dentre o grupo de licenciandos investigados, a maioria concebe que o ensino de Ciências exige a transposição do conhecimento acadêmico em conhecimento escolar. Sendo que esse último é produzido para finalidades específicas da escolarização e decorre de uma transposição do primeiro, conhecida como transposição didática. Lopes (2007), citando as pesquisas de Chevallard, afirma que a transposição didática envolve o

[...] "trabalho" de transformação de um objeto de saber a ensinar em um objeto de ensino, trabalho este que não é realizado exclusivamente, ou mesmo prioritariamente, por professores e professoras. Diferentes instâncias sociais atuam sobre os conteúdos de ensino, definindo os contornos de sua transformação no âmbito escolar (LOPES, 2007 , p. 200, grifo da autora). 
Por isso acreditamos que, na escola, vários saberes são construídos em interface com as políticas públicas, a comunidade, com os interesses da juventude e por meio da experiência dos docentes. Logo, em nossa opinião, ter uma visão ampla e crítica de um currículo em ação durante a formação acadêmicoprofissional seria um instrumento para desestabilizar a visão tradicional do ensino de Ciências biologizado e que prepara para um ano escolar posterior. Acreditamos que, ao vivenciar atividades que promovam a reflexão sobre a transposição didática, sobre como aprender a aprender e sobre como ensinar Ciências, o licenciando consiga integrar os conhecimentos adquiridos ao longo de sua formação.

Ademais, entre os alunos de $\mathrm{CN}$ e $\mathrm{CB}$, verificamos que há conformidade de que o trabalho de lecionar no Ensino Fundamental de Ciências exige mais do que somente conhecer o conteúdo a ser ensinado. Ou seja, para atuar nesse nível de escolaridade é preciso conhecer e vivenciar as práticas formativas presentes nos cursos de licenciatura. Referenda essa interpretação o fato de a maioria dos licenciandos acreditar que o trabalho de lecionar exige uma formação específica em Ciências da Natureza ${ }^{4}$ (tabela 6).

Tabela 6. Posicionamentos sobre a formação de professores

\begin{tabular}{lllllllll}
\hline \multirow{2}{*}{$\begin{array}{c}\text { Afirmações sobre a formação } \\
\text { de professores }\end{array}$} & \multicolumn{6}{c}{ Ciências Naturais (\%) } & \multicolumn{2}{c}{ Ciências Biológicas (\%) } \\
\cline { 2 - 8 } & CT & C & D & DT & CT & C & D & DT \\
\hline $\begin{array}{l}\text { Deve exigir formação docente específica } \\
\text { em Ciências da Natureza. }\end{array}$ & 73 & 19 & 8 & 0 & 45 & 25 & 30 & 0 \\
\hline $\begin{array}{l}\text { Para lecionar no Ensino Fundamental } \\
\text { de ciências basta saber o conteúdo a ser } \\
\text { ensinado. }\end{array}$ & 0 & 8 & 47 & 45 & 0 & 0 & 30 \\
\hline
\end{tabular}

Fonte: Dados adaptados de Reis (2016) e elaborados pelos autores.

$\mathrm{Na}$ fala de alguns dos licenciandos de $\mathrm{CB}$, em conversas informais e durante o preenchimento do questionário, vemos que a ideia de associar o conhecimento das disciplinas de conteúdo às práticas e vivências das disciplinas pedagógicas e pedagógicas de conteúdo é bem fundamentada. No trabalho de Reis (2016), vemos falas semelhantes entre os licenciandos de $\mathrm{CN}$ entrevistados pela autora. Em certas ocasiões, pudemos ouvir também, nessas conversas mais informais, as críticas que professores e alunos tecem sobre as disciplinas do curso, principalmente as de conteúdo disciplinar, nas quais os professores(as) não apresentam qualquer conhecimento sobre práticas pedagógicas e apenas "apresentam a matéria no datashow".

No caso dos cursos pesquisados, destacamos que os estudantes do curso de Licenciatura em Ciências da Natureza só têm essa opção de modalidade/habilitação para cursar, enquanto os estudantes de Licenciatura em Ciências Biológicas que participaram deste estudo também têm a opção de cursar o bacharelado posteriormente ao término da licenciatura. Por isso, acreditamos que os estudantes de licenciatura em CB que participaram da pesquisa optam pelo curso tradicional/ bacharelado pela oportunidade de continuarem seus estudos na pós-graduação das 
áreas de conteúdo, havendo a possibilidade de atuarem em outros setores como a indústria. Outro motivo é a falta de oferta de curso de Ciências da Natureza na região. Além disso, no caso de desejarem atuar na Educação Básica, poderão lecionar no Ensino Médio com um salário maior do que se atuassem no Ensino Fundamental.

\section{CONSIDERACְÕES FINAIS}

Nesta pesquisa desenvolvemos uma reflexão sobre a formação acadêmicoprofissional, promovida nos cursos de licenciatura em Ciências da Natureza e Ciências Biológicas, para a atuação no Ensino de Ciências da Natureza no nível Fundamental. Procuramos entender, por meio das visões dos discentes de ambos os cursos, quais são as relações e significados tecidos entre o conhecimento veiculado pelo seu curso, o Ensino de Ciências e a atuação no Ensino Fundamental. Dessa forma, nosso trabalho e coleta de dados ocorreu em conjunto com licenciandos do curso de Licenciatura em Ciências Biológicas da UFJF e por meio dos dados gerados pela pesquisa de Reis (2016) com estudantes de um curso de Licenciatura em Ciências da Natureza de uma universidade do Centro-Oeste.

Em vista de possibilitar essa reflexão e atingir os objetivos de pesquisa, os procedimentos metodológicos utilizados envolveram uma abordagem qualitativa com a aplicação de um questionário, composto por itens abertos e fechados, que nos possibilitou elencar características sobre as comunidades de licenciandos. Em nossas análises, destacamos os pontos de convergência e divergência entre os dois percursos formativos investigados.

Nesse sentido, a partir das visões dos licenciandos investigados, constatamos similaridades quanto às experiências vivenciadas durante a graduação. Para os discentes, seus cursos, detém pontos positivos quanto à aquisição geral de cultura e os conhecimentos necessários para atuar como profissional docente, além de reforçar em algum grau sua escolha pela profissão.

A carga horária, os conteúdos e as práticas das disciplinas pedagógicas foram apresentados como adequados e alinhados com a realidade vivida nas salas de aula do Ensino Fundamental. Podemos dizer ainda que, sobre as disciplinas pedagógicas, é mais fácil para os discentes visualizarem as relações interdisciplinares tecidas entre esses componentes curriculares quando contrapostos às relações entre disciplinas de conteúdo específico. Contudo, vale ressaltar que, para os licenciandos do curso de Ciências da Natureza, essa aproximação entre as diversas áreas do saber é mais clara do que para os licenciandos de Ciências Biológicas. Acreditamos que isso acontece porque o curso de Licenciatura em Ciências da Natureza tem como principal objetivo formar professores para atuar exclusivamente para o Ensino Fundamental, ao contrário da Licenciatura em Ciências Biológicas, que habilita também para o Ensino Médio.

Destacamos que ambos os cursos de formação deveriam rever suas matrizes curriculares, no que diz respeito à abordagem dos conhecimentos em Química, Física, Biologia, Geologia e Astronomia. Ter acesso aos conhecimentos essenciais dessas áreas seria importante para que o futuro professor refletisse sobre o currículo praticado no Ensino Fundamental. Acreditamos que, se isso ocorresse, não ouviríamos de colegas da Educação Básica: "agora, com a Base Nacional Comum 
Curricular (BNCC), temos Química no $6^{\circ}$ ano, como devemos proceder para preparar as aulas e deslocar o conteúdo que era dado no $9^{\circ}$ ano?" Ora, Lima e Silva (2012) já apontavam que os conhecimentos químicos, por exemplo, aparecem no cotidiano da sala de aula desde os anos iniciais e acompanham os estudantes ao longo da escolarização.

Logo, por que ainda dizemos "isso é da Química, isso é da Física, isso é da Biologia...”? Essa visão ainda está implícita, mesmo nos estudantes investigados que concordam em sua maioria que o Ensino de Ciências corresponde ao estudo de conceitos biológicos com exemplos da Química e da Física. Somos nós - professores formadores, professores da Educação Básica, estudantes de graduação - que perpetuamos essa visão, porque ainda não estamos imbuídos da visão de Ciências da Natureza como uma área dialógica, na qual devemos estar abertos à compreensão dos fenômenos e sua complexidade, independentemente dos conhecimentos de uma área ou de outra, que teremos de mobilizar.

Desse modo, acreditamos que uma formação acadêmico-profissional que contemple as discussões levantadas neste estudo possibilitaria aos licenciandos elaborar uma nova abordagem conceitual e procedimental para os conhecimentos disciplinares que compõem o currículo de Ciências da Natureza. Assim como desenvolver um olhar mais alargado, crítico e propositivo diante das normativas presentes na BNCC (BRASIL, 2017). Sem, contudo, a necessidade de estar sob o jugo de uma Base Nacional de Formação de Professores conforme prevê a Resolução 2/2019 (BRASIL, 2019) que atrela a formação docente à BNCC e que tem sido alvo de críticas pela comunidade acadêmica.

Todas essas considerações reforçam em nós a necessidade de ampliarmos o debate em torno do currículo de Ciências da Natureza, das políticas públicas, ou ausência delas, para o ensino do $6^{\circ}$ ao $9^{\circ}$ ano, da formação acadêmico-profissional e do perfil de atuação que esperamos do professor que leciona Ciências.

\section{REFERÊNCIAS}

AYRES, A.C.M.; SELLES, S.E. História da formação de professores: diálogos com a disciplina escolar de ciências no Ensino Fundamental. Ensaio, vol. 14, n. 02, p. 51-66, 2012.

BABBIE, E. Métodos de pesquisa de Survey. Belo Horizonte: ed. UFMG, 1999.

BERTI, V. P.; FERNANDEZ, C. O caráter dual do termo interdisciplinaridade na literatura, nos documentos oficiais educacionais e nos professores de química. Alexandria: Revista de educação em ciências e tecnologia, v. 8, n. 1, p. 153-180, 2015.

BIZZO, N. Ciências: fácil ou difícil? $1^{\text {a }}$ ed. São Paulo: Biruta, 2009.

BRASIL. Resolução CNE/CES no 7, de 11 de março de 2002 - Estabelece as Diretrizes Curriculares para os cursos de Ciências Biológicas (Bacharelado e Licenciatura). Disponível em: http://portal.mec.gov.br/cne/arquivos/pdf/CES07-2002.pdf. Acesso em: 25 ago. 2020.

BRASIL. Ministério da Educação. Base Nacional Comum Curricular, 2017. Disponível em: http://basenacionalcomum.mec.gov.br/images/BNCC_EI_EF_110518_versaofinal_site.pdf. Acesso em: 07 set. 2020. 
BRASIL. Resolução CNE/CP n 2, de 20 de dezembro de 2019. Define as Diretrizes Curriculares Nacionais para a Formação Inicial de Professores para a Educação Básica e institui a Base Nacional Comum para a Formação Inicial de Professores da Educação Básica (BNC-Formação). Disponível em: http://portal.mec.gov.br/docman/dezembro-2019-pdf/135951-rcp002-19/file. Acesso em 07 set. 2020.

CACHAPUZ, A. F. Do ensino das ciências: seis ideias que aprendi. In: CARVALHO, A. M. P.; CACHAPUZ, A. F.; GIL-PÉREZ, D. (org.) O ensino das ciências como compromisso científico e social: os caminhos percorridos. São Paulo: Cortez, p. 11-32, 2012.

CARVALHO, A. M. P; GIL-PEREZ, D. Formação de professores de ciências tendências e inovações. $10^{\mathrm{a}}$ ed. São Paulo: Cortez, 2011.

CUNHA, A. M. O.; KRASILCHK, M. A formação continuada de professores de ciências: percepções a partir de uma experiência. $23^{a}$ Reunião Anual da Associação Nacional de Pós-graduação e Pesquisa em Educação. Caxambu/MG, 24 a 28 de setembro, 2000.

DINIZ-PEREIRA, J. E. Formação Continuada de professores. In: OLIVEIRA, D. A.; DUARTE, A. M. C.; VIEIRA, L. M. F. Dicionário: trabalho, profissão e condição docente. Belo Horizonte: UFMG/Faculdade de Educação, CDROM, 2010.

DRIVER, R.; ASOKO, H.; LEACH, J.; MORITMER, E.; SCOTT, P. Construindo conhecimento científico na sala de aula. Química Nova na Escola, n. 9, p. 31-40, maio, 1999.

GATTI, B. A. Formação de professores no Brasil: características e problemas. Educação e Sociedade, vol. 31, n. 113, p. 1355-1379, out - dez, 2010.

GATTI, B. A.; NUNES, M.M.R, (org.). Formação de professores para o Ensino Fundamental: estudos de currículos das licenciaturas em pedagogia, língua portuguesa, matemática e ciências biológicas. São Paulo: FCC/DPE, n. 29, p. 123- 149, 2009.

GUNCKEL, K. L. Fulfilling Multiple Obligations: Preservice elementar teacher's use of an instructional model while learning to plan and teach Science. Science Education, vol. 97, n. 1, pp. $139-162,2013$.

FERNANDEZ, C. PCK - Conhecimento Pedagógico do Conteúdo: perspectivas e possibilidades para a formação de professores. In: VIII Encontro Nacional de Pesquisa em Educação e Ciências. Campinas, 2011. Anais Eletrônicos. Disponível em: http://www.nutes.ufrj.br/abrapec/viiienpec/ resumos/R0370-1.pdf. Acesso em: 08 ago. 2015.

LIMA, M. E. C. C.; AGUIAR JR. O. Ciências: Física e Química no Ensino Fundamental. Presença Pedagógica, v. 6, n. 31, jan./fev., p. 39-49, 2000.

LIMA, M. E. C. C.; AGUiAR JR. O. G.; BRAGA, S. A. M. Aprender Ciências: um mundo de materiais: livro do professor. Belo Horizonte: ed. UFMG, 1999.

LIMA, M. E. C.C.; BARBOZA, L. C. Ideias estruturadoras do pensamento químico: uma contribuição ao debate. Química Nova na Escola, n. 21, p. 39-43, maio, 2005.

LIMA, M. E. C. C.; LOUREIRO, M. B. Trilhas para ensinar ciências para crianças. $1^{a}$ edição. Belo Horizonte: Fino Traço, 2013.

LIMA, M. E. C.C.; SILVA, N. S. A. A Química no Ensino Fundamental: uma proposta em ação. In: ZANON, L. B.; MALDANER, O. A. (org.) Fundamentos e propostas de ensino de Química para a Educação Básica no Brasil. Ijuí: ed. Unijuí, p. 89-107, 2012.

LOPES, A. C. Currículo e epistemologia. Ijuí: ed. Unijuí, p. 232, 2007. 
A preparação para a docência no Ensino Fundamental na visão de licenciandos em Ciências Naturais e Ciências Biológicas

MALDANER, O. A.; SCHNETZLER, R. P. A necessária conjugação da pesquisa e do ensino na formação de professores e professoras. In: CHASSOT, A.; OLIVEIRA, J. R. (org.) Ciência, Ética e Cultura na Educação. São Leopoldo: ed. Unisinos, p. 195- 214, 1998.

MARTINS, et al. Por um novo currículo de ciências para as necessidades de nosso tempo. Presença Pedagógica, vol. 9, n. 51, mai./jun., 2003.

PIMENTA, S. G. Formação de professores: saberes da docência e identidade do professor. In: FAZENDA, I. (org.) Didática e Interdisciplinaridade. Campinas, SP: Papirus, p. 161 - 178, 1998.

RAZUCK, R. C. de S. R.; ROTTA, J. C. G. O curso de licenciatura em Ciências Naturais e a organização de seus estágios supervisionados. Ciência e Educação, vol. 20, n. 3, p. 739-750, 2014.

REIS, R. C.; Cursos de licenciatura em Ciências da Natureza: o conhecimento químico na formação de professores de Ciências para o Ensino Fundamental. Tese de Doutorado. Programa de Pós-graduação em Educação - Conhecimento e Inclusão Social em Educação. Universidade Federal de Minas Gerais, Belo Horizonte, p. 252, 2016.

REIS, R. C.; LOPES, J. G.S.; Transformação Química: Analisando o conteúdo abordado nos livros didáticos do Ensino Fundamental do 6. ${ }^{\circ}$ ao $9 .^{\circ}$ ano. In: XV Encontro Nacional de Ensino de Química. Brasília, 2011. Anais Eletrônicos. Disponível em: http://www.xveneq2010.unb.br/xveneq. htm. Acesso em: 04 jul. 2011.

SOMMERMAN, A. Inter ou Transdisciplinaridade?: da fragmentação disciplinar ao novo diálogo entre os saberes. São Paulo: Paulus, 2006.

TARDIF, M. Saberes docentes e formação profissional. 14ª ed., Petrópolis, RJ: Vozes, 2012.

TARDIF, M.; LESSARD, C. O ofício de professor: história, perspectivas e desafios internacionais. $3^{\text {a }}$ ed., Petrópolis, RJ: Vozes, 2009.

\section{NOTAS}

1 Utilizamos o termo Ciências da Natureza ao longo deste texto para nos referirmos à disciplina ofertada ao longo do ensino fundamental, por acreditarmos que necessitamos de uma denominação própria para o ensino de Ciências nesse nível.

2 Um outro motivo para a inserção desse tipo de disciplina nos cursos de licenciaturas decorre das considerações da área de Educação em Ciências no que diz respeito à utilização dos espaços não formais no ensino de Ciências na Educação Básica.

3 Denominamos as disciplinas pedagógicas e pedagógicas de conteúdo como disciplinas de ensino, pois essa é a expressão que os licenciandos utilizam para se referirem a elas.

4 Os alunos de CB também responderam sobre a exigência da formação docente específica em Ciências Biológicas, mas como a afirmativa não aparece nos questionários de $\mathrm{CN}$, optamos por não apresentar os dados neste trabalho.

Submetido em 13/05/2020

Aprovado em 11/09/2020

Revista Ensaio | Belo Horizonte | v.22 | e20581 | 2020 


\section{Contato:}

Rita de Cássia Reis

Universidade Federal de Juiz de Fora

Faculdade de Educação

Secretaria do Departamento de Educação

Campus Universitário - Bairro Martelos

CEP 36.036-330 - Juiz de Fora, MG - Brasil 